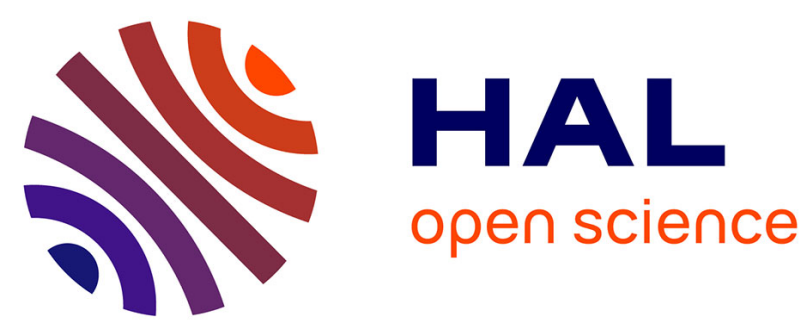

\title{
Decreased tryptophan and increased kynurenine levels in mastocytosis associated with digestive symptoms.
}

Sophie Georgin-Lavialle, Jean-Marie Launay, Francine Côté, Erinn Soucié, Angèle Soria, Gandhi Damaj, Daniela Silva Moura, Danielle Canioni, Katia

Hanssens, Marie-Olivia Chandesris, et al.

\section{To cite this version:}

Sophie Georgin-Lavialle, Jean-Marie Launay, Francine Côté, Erinn Soucié, Angèle Soria, et al.. Decreased tryptophan and increased kynurenine levels in mastocytosis associated with digestive symptoms.. Allergy, 2016, 71 (3), pp.416-420. 10.1111/all.12802 . hal-01269697

\section{HAL Id: hal-01269697 \\ https://hal.science/hal-01269697}

Submitted on 23 Mar 2016

HAL is a multi-disciplinary open access archive for the deposit and dissemination of scientific research documents, whether they are published or not. The documents may come from teaching and research institutions in France or abroad, or from public or private research centers.
L'archive ouverte pluridisciplinaire HAL, est destinée au dépôt et à la diffusion de documents scientifiques de niveau recherche, publiés ou non, émanant des établissements d'enseignement et de recherche français ou étrangers, des laboratoires publics ou privés. 
Title: Decreased tryptophan and increased kynurenine levels in mastocytosis associated with digestive symptoms

Short title: Kynurenine pathway in digestive mastocytosis.

\section{Authors:}

Sophie Georgin-Lavialle ${ }^{1,2, *}$, Jean-Marie Launay ${ }^{3}$, Francine Côté ${ }^{4}$, Erinn Soucié $^{5}$, Angèle Soria $^{2}$, Gandhi Damaj ${ }^{2,6}$, Daniela Silva Moura ${ }^{2}$, Danielle Canioni ${ }^{2,7}$, Katia Hanssens ${ }^{5}$, MarieOlivia Chandesris ${ }^{2,9}$, Stéphane Barète ${ }^{2}$, Patrice Dubreuil ${ }^{2,5}$, Olivier Lortholary ${ }^{2,8}$, Olivier Hermine $^{2,9}$ and Harry Sokol ${ }^{10, *}$.

French mast cell study group: Catherine Grandpeix-Guyodo, Julie Bruneau, Achille Aouba, Christian de Gennes, Isabelle Durieu, Olivier Fain, Isabelle Guichard, Christian Lavigne, Cristina Livideanu, Mohamed Hamidou, David Launay, Bernard Grosbois, Odile BeyneRauzy, Frederique Retornaz, Franck Nicolini.

\section{Affiliations:}

${ }^{1}$ Service de médecine Interne, Hôpital Tenon, Université Pierre et Marie Curie-Paris 6, Assistance Publique-Hôpitaux de Paris, 20 rue de la Chine, 75020 Paris.

${ }^{2}$ Centre de référence des mastocytoses, Université Paris Descartes, Sorbonne, Paris Cité, Hôpital Necker Enfants malades, Institut Imagine, Paris, France. 
${ }^{3}$ Laboratoire de biochimie et biologie moléculaire, Hôpital Lariboisière, Assistance PubliqueHôpitaux de Paris, INSERM U942, RTRS Santé Mentale.

${ }^{4}$ INSERM U1163 and CNRS ERL 8254 and Laboratory of physiopathology and treatment of hematological disorders Hôpital Necker-Enfants malades, Institut Imagine, 149 Rue des Sèvres, 75743 Paris Cedex 15, France.

5 INSERM UMR 891, Centre de Recherche en Cancérologie de Marseille, Laboratoire d'Hématopoïèse Moléculaire et Fonctionnelle, Marseille, France.

${ }^{6}$ Hématologie, Centre Hospitalier Universitaire, Faculté de Médecine, Avenue de la Côte de Nacre, 14000, Caen, France.

${ }^{7}$ Service d'Anatomie-Pathologique, Hôpital Necker-Enfants Malades, 149 rue de Sèvres, 75015 PARIS, Assistance Publique-Hôpitaux de Paris, Université Paris Descartes.

${ }^{8}$ Université Paris Descartes, Sorbonne, Paris Cité, Service des Maladies infectieuses et tropicales, Assistance Publique-Hôpitaux de Paris, Hôpital Necker-Enfants malades, IHU Imagine.

${ }^{9}$ Service d'hématologie adulte, Université Paris Descartes, Sorbonne, Paris Cité, Assistance Publique-Hôpitaux de Paris, Institut Imagine, Hôpital Necker-Enfants malades, 149 rue de Sèvres, 75015 PARIS.

${ }^{10}$ Service de Gastroentérologie et Nutrition, Hôpital Saint-Antoine, AP-HP, Université Pierre et Marie Curie-Paris 6, Paris, France. Equipe AVENIR, Laboratoire INSERM U1157 / UMR CNRS 7203, Université Pierre et Marie Curie 6, Paris, France. Equipe Interactions des bactéries commensales et probiotiques avec l'hôte, MICALIS, INRA, Jouy en Josas, France. 
*DHU I2B

Grant support: Sophie Georgin-Lavialle is recipient of a grant from SNFMI-Genzymemaladies rares and Centre National de la Recherche Scientifique (CNRS) and Assistance Publique Hôpitaux de Paris (AP-HP).

\section{Abbreviations:}

ASM: agressive systemic mastocytosis

AHNMD: associated clonal haematological non-MC-lineage disease.

CM: cutaneous mastocytosis

HPLC: high-performance liquid chromatography

IDO: Indoleamine 2,3-dioxygenase

ISM: indolent systemic mastocytosis

KYN: Kynurenine

MC: Mast Cell

5-HT: Serotonin

TRP: Tryptophan

WT: wild type 


\section{Correspondence:}

Dr Harry Sokol : Service de Gastroentérologie et Nutrition, Hôpital Saint-Antoine, AP-HP, Université Pierre et Marie Curie-Paris 6, Paris, France. Equipe AVENIR, Laboratoire INSERM U1057 / UMR CNRS 7203, Université Pierre et Marie Curie 6, Paris, France. Equipe Interactions des bactéries commensales et probiotiques avec l'hôte, MICALIS, INRA, Jouy en Josas, France.

Tel: 33149283162 ; Fax: 33149283188

E-mail: harry.sokol@aphp.fr

And

Dr Sophie Georgin-Lavialle, Service de médecine Interne, Hôpital Tenon, 20, rue de la Chine, 75020 Paris, Université Pierre et Marie Curie, Assistance Publique-Hôpitaux de Paris.

Tel: 3315601 72 04; Fax 33156017082

E-Mail: sophie.georgin-lavialle@aphp.fr

Disclosure: the authors declare no conflicts of interest.

Writing assistance: none

\section{Authorship contributions:}


Conception and design: S G-L, J-M L, FC, OH and HS

Biological measurements: J-M L

Gene sequencing: ES, KH, PD

Histological examination: DC

Provision of study materials: S G-L, AS, GD, M-O C, SB, OL, French mast cell study group, $\mathrm{OH}$ and $\mathrm{HS}$

Data collection and analysis: S G-L, J-M L, FC, DM, OH and HS

Manuscript writing: All authors

Final approval of manuscript: All authors

\section{Word count:}

Manuscript: 995

Abstract: 145 


\section{Abstract: (145 words)}

The main metabolism pathway of tryptophan is protein formation, but it can also be metabolized into serotonin and kynurenine. Indoleamine 2,3-dioxygenase (IDO) is the enzyme that catalyzes the degradation of tryptophan into kynurenine. Mastocytosis is a heterogeneous disease characterized by mast cell accumulation in various tissues with $57 \%$ of patients having gastrointestinal involvement. We studied tryptophan metabolism in mastocytosis patients displaying or not gastrointestinal features and healthy subjects $(n=26$ in each group). Mastocytosis patients with digestive symptoms displayed significantly increased kynurenine level and IDO activity as compared to healthy controls and mastocytosis patients without digestive symptoms. This could be linked to mast cell mediated digestive inflammation among patients with mastocytosis. This work is the first focusing on kynurenine pathway in a mast cell disease and could help to understand the pathogenesis of digestive features in mastocytosis as well as in other mast cell mediated diseases.

Key words: IDO, kynurenine, mastocytosis, serotonin, tryptophan. 


\section{Introduction}

Tryptophan (TRP) is an essential aminoacid which is the precursor of serotonin (5-HT) and its availability is the rate-limiting step in the synthesis of 5-HT (1). TRP is mostly involved in protein synthesis but is also the precursor of 5-HT or can be catabolized in the kynurenine (KYN) pathway (1). The main enzyme that catalyzes TRP conversion into KYN is indoleamine 2,3-dioxygenase (IDO, EC 1.13.11.17) (1)1-4)

. IDO activity can be induced in various immune cells including mast cells by inflammatory cytokines (2) (figure 1). TRP and its metabolites play a role in intestinal immunity, inflammation and gut motility through 5-HT (4)(4).

Mastocytosis is a heterogeneous disease characterized by mast cell accumulation in various tissues (6). Clinical manifestations of mastocytosis are related to MC mediators release and to pathological MC infiltration (6,7). Mastocytosis patients display disabling gastrointestinal symptoms $(59 \%)$ including $(9,10)$ diarrhoea, bloating, nausea and abdominal pain $(9,10)(9,10)$. Although, normal human MC are able to synthesize and release 5-HT (11), mastocytosis patients with diarrhea have abnormally low 5-HT (12).

Our aim was to investigate TRP metabolism in mastocytosis by comparing patients displaying gastrointestinal features to healthy controls and mastocytosis patients without gastrointestinal features. 


\section{Patients and methods}

\section{Patients and controls}

Adults with mastocytosis $(\mathrm{n}=52)$, as defined by the WHO international consensus criteria (6) were enrolled in a prospective national multicentric French study between 2007 and 2013. Patients with digestive features $(n=26)$, as defined by our previous report were compared to subjects with mastocytosis but without digestive features, matched in sex and age and randomly selected in the French mastocytosis center $(n=26)(9)$. Gastro-intestinal symptoms taken into account were bloating, abdominal pain, nausea $(\geq 5$ times/week), vomiting $(\geq 1$ time/week), and liquid stools (> 5 times/week). All patients provided their informed consent. The study was approved by the ethics committee at Necker hospital, and was carried out in compliance with the precepts of the Helsinki protocol. Healthy subjects with neither digestive symptoms nor mastocytosis were used as controls.

Serum tryptase, plasma tryptophan, whole blood serotonin and plasma kynurenine measurements (figure 2).

Serum total tryptase was measured using fluorescent enzyme-linked immunoassay (Unicap; Pharmacia) (14). Whole blood serotonin and plasma TRP rates and KYN were determined by high-performance liquid chromatography (HPLC) (16). IDO activity (= KYN/TRP ratio ) was calculated from absolute concentrations of KYN and TRP (17).

\section{Statistical analysis}

Statistical comparisons were performed using ANOVA and Wilcoxon non parametric tests (GraphPad Prism software version 5.01, GraphPad Software Inc., San Diego, CA) when appropriate. All reported $p$ values were two-tailed with a significance level of 0.05 


\section{Results}

\section{Main features of the study population (supplementary tables)}

The characteristics of the patients are described in supplementary Tables. As expected, all mastocytosis patients displayed significantly higher tryptase serum rates than healthy controls $(p<0.0001)$ (fig.2.A) Seven patients had undergone digestive endoscopic .explorations with proven mast cell infiltration on histological biopsies (Supplementary figure 1). In mastocytosis patients, digestive features were respectively: diarrhoea (53.9\%), abdominal pain $(42.3 \%)$, bloating (34.6\%), nausea (19.2\%) and vomiting (11.5\%).

Patients with digestive features displayed higher IDO activity and higher levels of Kynurenine.

Compared to healthy controls, mastocytosis patients displayed lower levels of TRP $(\mathrm{p}<0.0001)$ independently from GI symptoms. However, only those with gastrointestinal symptoms had higher IDO activity compared to controls (Figure 2.B; p<0.001). Moreover, KYN and IDO levels were higher in mastocytosis patients with gastrointestinal symptoms compared to patients without digestive features (Figure 2.C-D; $\mathrm{p}=0.01$ and 0.045 respectively).

Relationship between digestive features, tryptophan concentrations and IDO activity in mastocytosis.

Patients with more intense abdominal pain (score $>5$, on a scale from 0 to 10 ) tend to display minor TRP concentrations $(\mathrm{p}=0.055)$ and significant higher IDO activity $(\mathrm{p}=0.04)$. No other relationship was found between TRP level, IDO activity and other gastro-intestinal symptoms (Figure 2.E-F). 


\section{Discussion}

This is the first report studying TRP metabolism and the kynurenine pathway in mastocytosis with related GI symptoms. We found that mastocytosis patients displaying digestive features had higher IDO activity and decreased TRP levels as compared to healthy controls and to patients without digestive features. The decreased TRP level might be the consequence of an activation of the IDO pathway. This hypothesis is supported by the increased kynurenine level in mastocytosis patients with intestinal involvement. In these patients, IDO could be induced by the release of mast cell mediators in the digestive tract. Mast cells can secrete proinflammatory cytokines such as TNF alpha, interleukins 1 and 6, INF alpha (18) and are also able to express IDO (11). Moreover, recent work by Kawasaki showed that KYN catabolites are able to activate mast cells through an aryl hydrocarbon receptor which could stimulate IDO activity in mast cells, leading to kynurenine accumulation (19). The consequence could be a vicious circle activating more mast cells that, in turn, secrete proinflammatory cytokines leading to IDO activation.

Interestingly, gastro-intestinal lesions in mastocytosis patients could lead to an increase in intestinal permeability and circulating LPS which is known to stimulate proinflammatory cytokines and activate IDO, and thus the kynurenine formation (20).

Recent studies have focused on the role of tryptophan metabolism in irritable bowel syndrome (IBS). IBS patients share many features with mastocytosis patients displaying intestinal involvement, such as abdominal pain, bloating and infiltration by mast cells in the gut mucosa $(21)(21)(21)$. Taken together, it is interesting to speculate that these two clinically close entities could share some pathogenenic aspects involving gut mucosal immune homeostasis possibly linked to the microbiota (21). 
The presence of decreased TRP and 5-HT levels in mastocytosis patients could suggest a link to functional symptoms described by patients. Antihistaminics could be useful to prevent mast cell mediator liberation if they are specific for TPH1. Some authors have suggested the use of tryptophan hydroxylase inhibitors for irritable bowel syndrome which could be tried in digestive mastocytosis (22).

In conclusion, this study provides new elements in the pathogenesis of digestive features in mastocytosis which could open new therapeutic strategy in these patients as well as in gastrointestinal diseases such as IBS that share common pathogenenic aspects. 


\section{References}

1. Le Floc'h N, Otten W, Merlot E. Tryptophan metabolism, from nutrition to potential therapeutic applications. Amino Acids 2011;41:1195-1205.

2. Capuron L, Miller AH. Cytokines and psychopathology: lessons from interferon-alpha. Biol Psychiatry 2004;56:819-824.

3. Cherayil BJ. Indoleamine 2,3-dioxygenase in intestinal immunity and inflammation. Inflamm Bowel Dis 2009;15:1391-1396.

4. Ciorba MA. Indoleamine 2,3 dioxygenase in intestinal disease. Curr Opin Gastroenterol 2013;29:146-152.

5. Myint AM. Kynurenines: from the perspective of major psychiatric disorders. FEBS $J$ 2012;279:1375-1385.

6. Akin C, Valent P. Diagnostic criteria and classification of mastocytosis in 2014. Immunol Allergy Clin North Am 2014;34:207-218.

7. Carter MC, Metcalfe DD, Komarow HD. Mastocytosis. Immunol Allergy Clin North Am 2014;34:181-196.

8. Hermine O, Lortholary O, Leventhal PS, Catteau A, Soppelsa F, Baude C et al. Casecontrol cohort study of patients' perceptions of disability in mastocytosis. PloS One 2008;3:e2266.

9. Sokol H, Georgin-Lavialle S, Canioni D, Barete S, Damaj G, Soucie E et al. Gastrointestinal manifestations in mastocytosis: a study of 83 patients. J Allergy Clin Immunol 2013;132:866-873.e1-3.

10. Sokol H, Georgin-Lavialle S, Grandpeix-Guyodo C, Canioni D, Barete S, Dubreuil P et al. Gastrointestinal involvement and manifestations in systemic mastocytosis. Inflamm Bowel Dis 2010;16:1247-1253.

11. Kushnir-Sukhov NM, Brown JM, Wu Y, Kirshenbaum A, Metcalfe DD. Human mast cells are capable of serotonin synthesis and release. J Allergy Clin Immunol 2007;119:498-499.

12. Kushnir-Sukhov NM, Brittain E, Scott L, Metcalfe DD. Clinical correlates of blood serotonin levels in patients with mastocytosis. Eur J Clin Invest 2008;38:953-958.

13. Bodemer C, Hermine O, Palmérini F, Yang Y, Grandpeix-Guyodo C, Leventhal PS et al. Pediatric mastocytosis is a clonal disease associated with D816V and other activating cKIT mutations. J Invest Dermatol 2010;130:804-815.

14. Georgin-Lavialle S, Lhermitte L, Baude C, Barete S, Bruneau J, Launay J-M et al. Blood CD34-c-Kit+ cell rate correlates with aggressive forms of systemic mastocytosis and behaves like a mast cell precursor. Blood 2011;118:5246-5249. 
15. Sperr WR, Jordan JH, Baghestanian M, Kiener HP, Samorapoompichit P, Semper H et al. Expression of mast cell tryptase by myeloblasts in a group of patients with acute myeloid leukemia. Blood 2001;98:2200-2209.

16. Kema IP, Schellings AM, Hoppenbrouwers CJ, Rutgers HM, de Vries EG, Muskiet FA. High performance liquid chromatographic profiling of tryptophan and related indoles in body fluids and tissues of carcinoid patients. Clin Chim Acta Int J Clin Chem 1993;221:143-158.

17. Fujigaki S, Saito K, Takemura M, Fujii H, Wada H, Noma A et al. Species differences in L-tryptophan-kynurenine pathway metabolism: quantification of anthranilic acid and its related enzymes. Arch Biochem Biophys 1998;358:329-335.

18. Widner B, Ledochowski M, Fuchs D. Interferon-gamma-induced tryptophan degradation: neuropsychiatric and immunological consequences. Curr Drug Metab 2000;1:193-204.

19. Kawasaki H, Chang H-W, Tseng H-C, Hsu S-C, Yang S-J, Hung C-H et al. A tryptophan metabolite, kynurenine, promotes mast cell activation through aryl hydrocarbon receptor. Allergy 2014;69:445-452.

20. Wirthgen E, Tuchscherer M, Otten W, Domanska G, Wollenhaupt K, Tuchscherer A et al. Activation of indoleamine 2,3-dioxygenase by LPS in a porcine model. Innate Immun 2014;20:30-39.

21. Berstad A, Raa J, Valeur J. Tryptophan: 'essential' for the pathogenesis of irritable bowel syndrome? Scand J Gastroenterol 2014;:1-6.

22. Catanzaro R, Occhipinti S, Calabrese F, Anzalone MG, Milazzo M, Italia A et al. Irritable bowel syndrome: new findings in pathophysiological and therapeutic field. Minerva Gastroenterol Dietol 2014;60:151-163. 


\section{Figure legends}

Figure 1. Schematic representation of tryptophan metabolism pathway

Cytokines (interleukines 1 and 6, TNF $\square$ ) synthetized by activated mast cells in mastocytosis are able to induce the enzyme indoleamine-2,3-dioxygenase (IDO) that catabolizes TRP into KYN, thereby reducing the availability of TRP for 5-HT synthesis.

Figure 2. Tryptophan metabolism in Mastocytosis

Tryptase level (panel A), Tryptophan level (panel B), Kynurenine level (panel C) and IDO activity (panel D) in blood of mastocytosis patients with or without digestive symptoms and in healthy controls. Tryptophan level (panel E) and IDO activity (panel F) is associated with abdominal pain in mastocytosis patients with gastro-intestinal symptoms. *, p<0.05; ***, $\mathrm{p}<0.001$. IDO activity is the result of the ratio KYN/TRP expressed in percentage.

\section{Supplementary figure 1 .}

Examples of MC infiltration in the gastrointestinal tract. Panel A. Duodenal mucosa biopsy of a patient with mastocytosis showing a huge infiltration by round monomorphic cells suggesting mast cells (H\&E x200). Panel B. Immunohistochemistry staining with anti-CD117 antibody showing large aggregates of mast cells in the lamina propria with diffuse expression of c-kit (CD117) antibody x200. 
Supplementary Table 1: Comparison of main features of mastocytosis patients with or without digestive symptoms.

\begin{tabular}{|c|c|c|c|c|}
\hline & Digestive symptoms & $\begin{array}{l}\text { No digestive } \\
\text { symptoms }\end{array}$ & Healthy controls & $\begin{array}{l}\text { p Digestive sympton } \\
\text { vs No digestive } \\
\text { symptoms }\end{array}$ \\
\hline $\begin{array}{l}\text { Age at diagnosis } \\
\text { (years) } \\
\text { median (range) }\end{array}$ & $\begin{array}{c}50 \\
(25-65)\end{array}$ & $\begin{array}{c}40 \\
(26-71)\end{array}$ & $\begin{array}{c}50 \\
(25-65)\end{array}$ & 0.12 \\
\hline $\begin{array}{l}\text { Female/Male } \\
\text { WHO stage }\end{array}$ & $22 / 4$ & $18 / 8$ & $22 / 4$ & 0.11 \\
\hline $\mathbf{C M}$ & 3 & 0 & - & \\
\hline ISM & 19 & 23 & - & 0.3 \\
\hline ASM & 3 & 2 & - & \\
\hline SM-AHNMD & 1 & 1 & - & \\
\hline
\end{tabular}




\begin{tabular}{|c|c|c|c|c|}
\hline \multicolumn{5}{|l|}{ KIT mutation } \\
\hline D816V & 21 & 24 & - & 0.22 \\
\hline No (WT ) & 5 & 2 & - & \\
\hline \multicolumn{5}{|l|}{ Laboratory data, } \\
\hline \multicolumn{5}{|l|}{ median (range) } \\
\hline Tryptase (ng/L) & $27.2(11.3-257)$ & $30.5(2.7-161)$ & $4.35(2.8-5.3)$ & 0.7 \\
\hline 5-HT (nM) & $272(34-1278)$ & $226.5(49-910)$ & $352.5(147-708)$ & 0.09 \\
\hline Tryptophan $(\boldsymbol{\mu M})$ & $45.8(22.2-60)$ & $46.2(12.2-59.2)$ & $52.4(48.3-57.3)$ & 0.6 \\
\hline Kynurenine ( $\boldsymbol{\mu M})$ & $3.9(1.9-5.3)$ & $2.9(1.6-4.6)$ & $3.4(1.9-4.7)$ & 0.01 \\
\hline IDO (\%) & $8.7(3.1-18.1)$ & $6.65(3.7-14.7)$ & $6.16(3.8-9.4)$ & 0.04 \\
\hline
\end{tabular}

Abbreviations: CM: cutaneous mastocytosis; ISM: indolent systemic mastocytosis; ASM:

agressive systemic mastocytosis; AHNMD: associated clonal haematological non-MC-lineage disease. 5-HT: serotonin; IDO: Indoleamine 2,3-dioxygenase;

${ }^{1} \mathrm{P}$ was calculated according to chi squared Fisher's exact test or Mann-Whitney test. 
Supplementary table 2. Main features of mastocytosis patients with digestive features

\begin{tabular}{|c|c|c|c|c|c|c|c|c|}
\hline $\begin{array}{l}\text { Patient } \\
\text { number }\end{array}$ & Age & Sex & KIT sequencing & $\begin{array}{l}\text { WHO } \\
\text { stage }\end{array}$ & $\begin{array}{c}\text { Serum } \\
\text { Tryptase }\end{array}$ & $\begin{array}{l}\text { Whole } \\
\text { blood } \\
\text { 5-HT }\end{array}$ & $\begin{array}{c}\text { Plasma } \\
\text { Tryptophan }\end{array}$ & $\begin{array}{c}\text { IDO } \\
\text { activity }\end{array}$ \\
\hline 1 & 54 & $\mathrm{~F}$ & D816V & ISM & 18.5 & 219 & 47 & 9.2 \\
\hline 2 & 25 & $\mathrm{~F}$ & $\mathrm{D} 816 \mathrm{~V}$ & $\begin{array}{c}\text { SM- } \\
\text { AHNMD }\end{array}$ & 19 & 653 & 43 & 8.8 \\
\hline 3 & 51 & $\mathrm{~F}$ & $\mathrm{D} 816 \mathrm{~V}$ & ASM & 32 & 797 & 52 & 7.7 \\
\hline 4 & 62 & $\mathrm{~F}$ & D816V & ISM & 15.5 & 436 & 31.7 & 13.2 \\
\hline 5 & 39 & $\mathrm{M}$ & D816V & ISM & 31.5 & 429 & 58 & 7.1 \\
\hline 6 & 33 & $\mathrm{~F}$ & WT & ISM & 15.6 & 173 & 47 & 10 \\
\hline 7 & 57 & $\mathrm{~F}$ & D816V & ASM & 37 & 226 & 49 & 9.4 \\
\hline 8 & 51 & $\bar{M}$ & $\mathrm{D} 816 \mathrm{~V}$ & ISM & 48 & 665 & 44.5 & 9.7 \\
\hline 9 & 39 & $\mathrm{~F}$ & $\mathrm{D} 816 \mathrm{~V}$ & ISM & 68 & 1033 & 61 & 3.1 \\
\hline 10 & 63 & $\mathrm{~F}$ & $\mathrm{D} 816 \mathrm{~V}$ & ISM & 82 & 34 & 28 & 18 \\
\hline 11 & 62 & $\mathrm{~F}$ & $\mathrm{D} 816 \mathrm{~V}$ & ISM & 19 & 203 & 48 & 10.4 \\
\hline 12 & 50 & $\mathrm{M}$ & $\mathrm{D} 816 \mathrm{~V}$ & $\mathrm{CM}$ & 13 & 152 & 49 & 6.5 \\
\hline 13 & 50 & $\mathrm{~F}$ & WT & ISM & 200 & 130 & 30 & 8 \\
\hline 14 & 45 & $\mathrm{~F}$ & WT & ISM & 15 & 1278 & 29 & 8.6 \\
\hline 15 & 45 & $\mathrm{~F}$ & $\mathrm{D} 816 \mathrm{~V}$ & ISM & 39 & 247 & 57 & 4.75 \\
\hline
\end{tabular}




\begin{tabular}{|c|c|c|c|c|c|c|c|c|}
\hline 16 & 47 & $\mathrm{~F}$ & D816V & ISM & 177 & 387 & 54.5 & 9.7 \\
\hline 17 & 65 & $\mathrm{~F}$ & D816V & ISM & 257 & 250 & 51 & 7.5 \\
\hline 18 & 57 & $\mathrm{M}$ & D816V & ISM & 228 & 321 & 44 & 6.3 \\
\hline 19 & 40 & $\mathrm{~F}$ & D816V & ISM & 79 & 266 & 41 & 10.3 \\
\hline 20 & 43 & $\mathrm{~F}$ & D816V & ISM & 11.4 & 110 & 22 & 17.6 \\
\hline 21 & 37 & $\mathrm{~F}$ & WT & ASM & 95 & 192 & 60 & 4.3 \\
\hline 22 & 38 & $\mathrm{~F}$ & D816V & ISM & 21 & 278 & 34 & 8.6 \\
\hline 23 & 54 & $\mathrm{~F}$ & WT & ISM & 16.5 & 471 & 41.6 & 11.5 \\
\hline 24 & 53 & $\mathrm{~F}$ & D816V & ISM & 15 & 310 & 48 & 5.2 \\
\hline 25 & 57 & $\mathrm{~F}$ & D816V & $\mathrm{CM}$ & 23 & 240 & 45 & 7.4 \\
\hline 26 & 43 & $\mathrm{~F}$ & D816V & $\mathrm{CM}$ & 11 & 284 & 41 & 9 \\
\hline
\end{tabular}


Supplementary table 3. Main features of mastocytosis patients without digestive features

\begin{tabular}{|c|c|c|c|c|c|c|c|c|}
\hline $\begin{array}{l}\text { Patient } \\
\text { number }\end{array}$ & Age & Sex & $\begin{array}{c}\text { KIT } \\
\text { sequencing }\end{array}$ & WHO stage & $\begin{array}{l}\text { Serum } \\
\text { tryptase }\end{array}$ & $\begin{array}{l}\text { Whol } \\
\text { e } \\
\text { bloo } \\
\text { d 5- } \\
\text { HT }\end{array}$ & $\begin{array}{c}\text { Plasma } \\
\text { Tryptophan }\end{array}$ & IDO \\
\hline 1 & 37 & $F$ & D816V & ISM & 5.5 & 233 & 40.5 & 7.65 \\
\hline 2 & 31 & $\mathrm{~F}$ & D816V & ISM & 3.8 & 374 & 48.6 & 5.35 \\
\hline 3 & 60 & $\mathrm{~F}$ & D816V & ISM & 22 & 95 & 12.2 & 14.7 \\
\hline 4 & 34 & $\mathrm{~F}$ & WT & $\overline{\mathrm{ASM}}$ & 30 & 157 & 32.3 & 10.8 \\
\hline 5 & 51 & $F$ & D816V & ISM & 21.4 & 393 & 46.8 & 6.8 \\
\hline 6 & 39 & $\mathrm{~F}$ & D816V & ISM & 25 & 98 & 35.7 & 12.9 \\
\hline 7 & 52 & $\mathrm{H}$ & D816V & ISM & 31 & 120 & 27.9 & 16.5 \\
\hline 8 & 46 & $\mathrm{H}$ & D816V & ASM & 161 & 289 & 50 & 7.2 \\
\hline 9 & 28 & $\mathrm{~F}$ & D816V & ISM & 8.6 & 118 & 37.4 & 4.2 \\
\hline 10 & 50 & $\mathrm{H}$ & D816V & ISM & 47.7 & 665 & 44.5 & 9.6 \\
\hline 11 & 39 & $F$ & D816V & ISM & 30 & 241 & 56.6 & 6.7 \\
\hline 12 & 36 & $F$ & D816V & ISM & 27 & 910 & 59.2 & 4 \\
\hline 13 & 36 & $\mathrm{~F}$ & WT & ISM & 40 & 105 & 44.8 & 6 \\
\hline 14 & 44 & $F$ & D816V & ISM & 90 & 221 & 56.8 & 4.75 \\
\hline
\end{tabular}




\begin{tabular}{|c|c|c|c|c|c|c|c|c|}
\hline 15 & 32 & $\mathrm{~F}$ & D816V & ISM & 19 & 335 & 50.2 & 5.6 \\
\hline 16 & 66 & $\mathrm{H}$ & D816V & ISM & 35.6 & 85 & 45.7 & 6.6 \\
\hline 17 & 71 & $\mathrm{H}$ & D816V & ISM & 43 & 199 & 49.6 & 5.3 \\
\hline 18 & 42 & $\mathrm{H}$ & D816V & ISM & 47 & 404 & 56.7 & 3.7 \\
\hline 19 & 48 & $\bar{F}$ & $\mathrm{D} 816 \mathrm{~V}$ & ISM & 37 & 128 & 40.2 & 6.2 \\
\hline 20 & 26 & $\mathrm{H}$ & D816V & ISM & 57 & 49 & 47.6 & 6.7 \\
\hline 21 & 55 & $\mathrm{~F}$ & D816V & ISM & 80 & 338 & 39 & 4.8 \\
\hline 22 & 38 & $\mathrm{H}$ & $\mathrm{D} 816 \mathrm{~V}$ & ISM & 45 & 232 & 49 & 5.9 \\
\hline 23 & 41 & $\mathrm{~F}$ & D816V & ISM & 6 & 156 & 57.4 & 4.5 \\
\hline 24 & 62 & $\mathrm{H}$ & D816V & $\begin{array}{c}\text { SM- } \\
\text { AHNMD }\end{array}$ & 152 & 203 & 46.8 & 6.8 \\
\hline 25 & 35 & $F$ & D816V & ISM & 29 & 242 & 33.4 & 10.2 \\
\hline 26 & 37 & $\mathrm{~F}$ & D816V & ISM & 2.7 & 241 & 37 & 11.1 \\
\hline
\end{tabular}

